\title{
Synthesis of a series of soluble main-chain chiral nonracemic poly(alkyl-aryl ketone)
}

\author{
P. Wei $i^{1}$, D. Wang 1 , Z. Wu $u^{1}, X . B i^{2 *}$ \\ ${ }^{1}$ Department of Chemistry, University of Missouri-Kansas City, Kansas City, MO 64110, USA \\ 2Department of Physical Sciences, Charleston Southern University, Charleston, SC 29406, USA
}

Received 5 March 2008; accepted in revised form 26 April 2008

\begin{abstract}
A series of main-chain chiral polyketones have been synthesized through condensation polymerization of a dihalide and a diketone with optically pure binaphthyl moiety as linkage in the polymer backbone. The solubility of the polymers can be easily enhanced by substituents at the alpha position next to the carbonyl groups. Reducing the steric hindrance of the substituents in the monomers increases the reactivity of the polymerization. The chiral polymers exhibit large optical rotations. Circular Dichroism (CD) spectra of the polymers are similar to those of the corresponding monomers. The novel synthetic strategy may have great impact on future development of palladium catalyzed condensation polymerizations. The highly soluble chiral polymers synthesized allow for preparation of materials in the form of thin films and have potentials applications in various areas such as chiral separation and recognition.
\end{abstract}

Keywords: polymer synthesis, molecular engineering, main-chain chiral polyketone, polycondensation

\section{Introduction}

Main-chain chiral polymers are of great interest because of their important applications in chiral separation and recognition [1-4]. In order to achieve such goals materials must be stable and possess functional groups. Considerable attention has been focused on the synthesis of optically active polymers with chirality in the main-chain because the polymers typically exist or have the tendency to form helical and rigid-rod configuration, which offers enhanced capability in chiral applications [5-8]. Although it has constantly been great synthetic challenges in constructing mainchain chiral polymers, there are a number of strategies developed to build chirality into the polymer backbones. These include the polymerization of chiral monomers and asymmetric polymerization of achiral monomers using chiral catalysts [3, 9-16]. The asymmetric polymerization requires a careful design of catalysts and laborious screening for the right chiral ligands. Direct polymerization of chiral monomers usually results in polymers of decreased processibility, which has been overcome by attaching long alkyl substituents [5, 6]. The drawback is the alteration of rheological behavior of the polymers.

Polyketones are a class of high performance materials that have attracted a great deal of attention due to their high thermal stability, which is a result of the incorporation of thermally stable carbonyl and/or aromatic groups in the polymer backbones [17-19]. These polymers typically exhibit high glass transition temperatures and high melting points [17], which makes them ideal candidates for use as stationary phase in chromatography applications. Aromatic polyketones are synthesized by Friedel-Crafts or nucleophilic aromatic substitution reactions [20-25]. The materials are usually insolu-

*Corresponding author, e-mail: xbi@csuniv.edu

(C) BME-PT and GTE 
ble and intractable. Aliphatic polyketones have been prepared through the copolymerization of carbon monoxide with ethylene or $\alpha$-olefins $[9,26-$ 29]. Previously we have developed a new polymerization route for the construction of aromatic alkyl polyketones using palladium phosphine complexes [30]. To further extend our research in new polymer synthesis, we have developed the strategy of synthesizing main-chain chiral polyketones using palladium catalyzed condensation polymerization. The chirality of the polyketone main chain is achieved by utilizing chiral binaphthyl moiety, which has been previously reported as chiral monomer for other polymer synthesis [31-37]. The synthesized chiral polyketones have been extensively characterized by ${ }^{1} \mathrm{H}$ and ${ }^{13} \mathrm{C}$ NMR, gel permeation chromatography (GPC), polarimeter, UV-Vis spectrometry and circular dichroism (CD). To the best our knowledge, this is the first time that soluble main-chain chiral aliphatic aromatic polyketones are reported.

\section{Experimental section}

\subsection{Materials and methods}

Solvents (hexane, benzene, diethyl ether) were predried using $3 \AA$ molecular sieves, degassed and stirred over benzophenone ketyl. The dried and degassed solvents were vacuum-transferred into a flame-dried flask equipped with a Teflon valve and stored under $\mathrm{N}_{2}$. Other solvents were distilled from either $\mathrm{CaH}_{2}$ or $\mathrm{P}_{2} \mathrm{O}_{5}$ before use. All the chemicals used were purchased from either the Aldrich Chemical Company or ACROS Organics. Optically pure binaphthol was resolved according to literature procedures [38]. Optical rotation was measured on a Rudolph Autopol III polarimeter and a JASCO-J-720 circular dichroism spectroscopy. ${ }^{1} \mathrm{H}$ NMR spectra were measured with a Bruker AM 250 (250 MHz) spectrometer. ${ }^{13} \mathrm{C}$ NMR spectra were recorded at $62.9 \mathrm{MHz}$ on a Brucker AM 250 spectrometer. Molecular weights were determined by gel permeation chromatography (GPC) equipped with a Waters 410-differential refractometer. A flow rate of $1.0 \mathrm{ml} / \mathrm{min}$ was used and samples were prepared in THF. Polystyrene standards were used for calibration.

\subsection{Synthesis}

Synthesis of $(R)-(+)-6,6^{\prime}$-dibromo-2,2'-dihydroxy$1,1^{\prime}$-binaphthyl $(\mathbf{1})$

This compound was synthesized in $97.5 \%$ yield (mp $208-209^{\circ} \mathrm{C}$ ) from optically pure $(R)-(+)-2,2^{\prime}-$ dihydroxy-1,1'-binaphthyl following a reported procedure [39]. Characterizations by ${ }^{1} \mathrm{H}$ NMR are consistent with reported data.

Synthesis of $(R)-(+)-6,6^{\prime}$-dibromo-2,2'-dimethoxy1,1'-binaphthyl (2)

(R)-(+)-6,6'-dibromo-2,2' -dihydroxy-1,1'-binaphthyl (3.99 g, $8.49 \mathrm{mmol})$ and anhydrous $\mathrm{K}_{2} \mathrm{CO}_{3}$ (3.5 g, $27.3 \mathrm{mmol})$ were added in dry $\mathrm{CH}_{3} \mathrm{CN}$ $(50 \mathrm{ml})$ followed by a slow addition of $\mathrm{CH}_{3} \mathrm{I}$ $(1.56 \mathrm{ml}, 25 \mathrm{mmol})$. The mixture was refluxed for two days and cooled to room temperature before poured into $200 \mathrm{ml}$ of water. The mixture was filtered and recrystallized from methylene chloridebenzene (1:1 mixture) to give the desired product (3.8 g, yield 89.5\%). ${ }^{1} \mathrm{H}$ NMR $\left(\mathrm{CDCl}_{3}\right): \delta 4.12$ (s, $\left.\mathrm{OCH}_{3}, 6 \mathrm{H}\right), 7.30$ (d, $\left.2 \mathrm{H}\right), 7.64$ (d, $\left.2 \mathrm{H}\right), 7.83$ (d, $2 \mathrm{H}), 8.26(\mathrm{~d}, 2 \mathrm{H}), 8.36(\mathrm{~s}, 2 \mathrm{H}) .{ }^{13} \mathrm{C}$ NMR $\left(\mathrm{CDCl}_{3}\right): \delta 56.62,114.8,117.3,118.9,126.8$, 128.7, 129.7, 129.8, 130.1, 132.3, 155.1.

\section{Synthesis of $(R)-(+)-6,6^{\prime}$-diiodo-2,2'-dimethoxy- binaphthyl (3)}

A solution of $(R)-(+)-6,6^{\prime}$-dibromo-2,2'-dimethoxybinaphthol $(4.72 \mathrm{~g}, 0.01 \mathrm{~mol})$ and $\mathrm{KI}(16.6 \mathrm{~g}$, $0.1 \mathrm{~mol})$ in DMF (80 ml) was prepared and brought to reflux. While the solution was still warm, $\mathrm{NiBr}_{2}$ $(1.4 \mathrm{~g}, 6.48 \mathrm{mmol})$ and tri-n-butyl phosphine $(1.0 \mathrm{ml}, 4.0 \mathrm{mmol})$ was added. Refluxing was continued overnight. Upon cooling, the solution was diluted with $200 \mathrm{ml}$ of benzene, and washed with several portions of water and dried over $\mathrm{MgSO}_{4}$. The solvent was evaporated and the solid was recrystallized thrice from $\mathrm{CH}_{2} \mathrm{Cl}_{2} / \mathrm{Et}_{2} \mathrm{O}$ solvent mixture $(1: 1)$ to give a yellowish powder (yield $78 \%) .{ }^{1} \mathrm{H} \mathrm{NMR}\left(\mathrm{CDCl}_{3}\right): \delta 4.11\left(\mathrm{~s}, \mathrm{OCH}_{3}, 6 \mathrm{H}\right)$, 7.30 (d, $2 \mathrm{H}), 7.63(\mathrm{~d}, 2 \mathrm{H}), 7.83(\mathrm{~d}, 2 \mathrm{H}), 8.25$ (d, $2 \mathrm{H}), 8.36(\mathrm{~s}, 2 \mathrm{H}) .{ }^{13} \mathrm{C} \mathrm{NMR}\left(\mathrm{CDCl}_{3}\right): \delta 56.9$, $88.8,114.9,119.1,127.1,128.9,131.0,132.9$, 135.1, 136.8, 155.5. Element analysis: Calculated: C $46.67 \%$, H $2.85 \%$. Found: C $46.23 \%$, H $2.82 \%$. 
Synthesis of (R)-(-)-6,6'-dipropionoyl-2,2'dimethoxy-1, 1'-binaphthyl (4)

To a Schlenk flask was charged with $(R)-(+)-6,6^{\prime}-$ dibromo-2,2'-dimethoxy-1,1'-binaphthyl (1.89 g, $4.0 \mathrm{mmol})$ and dry THF (50 ml). The solution was cooled to $-78^{\circ} \mathrm{C}$ in a dry ice-acetone bath and a hexane solution of BuLi (1.6 M, $5.52 \mathrm{ml}, 8.8 \mathrm{mmol})$ was added slowly. After the mixture was stirred for 2 hours, $\mathrm{N}, \mathrm{N}^{\prime}$-dimethylpropionamide $(1.1 \mathrm{ml}$, $10 \mathrm{mmol}$ ) was added dropwise via a syringe. The solution was allowed to warm to room temperature overnight and was quenched by adding $10 \% \mathrm{HCl}$ $(50 \mathrm{ml})$ solution. The organic layer was separated, dried over $\mathrm{MgSO}_{4}$ and evaporated. The residue was purified by flash chromatography on silica gel using benzene-ethyl acetate (15:1) as eluent to give pure product $0.935 \mathrm{~g}$ (yield $54.9 \%$ ). ${ }^{1} \mathrm{H}$ NMR $\left(\mathrm{CDCl}_{3}\right): \delta 1.27$ (t, $\left.\mathrm{CH}_{3}, 6 \mathrm{H}\right), 3.09$ (q, $\left.\mathrm{CH}_{2}, 4 \mathrm{H}\right)$, $3.81\left(\mathrm{~s}, \mathrm{OCH}_{3}, 6 \mathrm{H}\right), 7.13(\mathrm{~d}, 2 \mathrm{H}), 7.55(\mathrm{~d}, 2 \mathrm{H})$, $7.81(\mathrm{~d}, 2 \mathrm{H}), 8.16$ (d, $2 \mathrm{H}), 8.55$ (s, $2 \mathrm{H}) .{ }^{13} \mathrm{C}$ NMR $\left(\mathrm{CDCl}_{3}\right): \delta 8.6,31.9,56.7,114.5,118.9,124.7$, 125.5, 128.2, 130.2, 131.8, 132.3, 136.3, 157.1, 200.8. Element analysis: Calculated: C $78.85 \%$, H 6.14\% Found: C 78.43\%, H 6.05\%.

\section{Synthesis of (S)-(-)-2,2'-dimethoxy-1,1'-binaphthyl} (5)

The optically pure $(S)-(-)-2,2^{\prime}$-dimethoxy-1, $1^{\prime}$ binaphthyl was prepared by the reaction of $(S)-(-)-$ 2,2'-dihydroxy-1,1'-binaphthyl with $\mathrm{CH}_{3} \mathrm{I}$ using the similar procedure as described in the preparation of $(R)-(+)-6,6^{\prime}$-dibromo-2,2'-dimethoxy-1,1'-binaphthyl.

Synthesis of (S)-(-)-3,3'-dipropionoyl-2,2'dimethoxy-1,1'-binaphthyl (7)

To a Schlenk flask was charged with $(S)-(-)-2,2^{\prime}-$ dimethoxy-1,1'-binaphthyl (1.57 g, $5 \mathrm{mmol})$, TMEDA (1.6 ml, $10.5 \mathrm{mmol})$ and dry ether $(75 \mathrm{ml})$. A hexane solution of $n$-butyl lithium $(1.6 \mathrm{M}, 7.1 \mathrm{ml}$, $11.3 \mathrm{mmol}$ ) was added dropwise. The mixture was stirred for 3 hours at room temperature, and cooled to $-78^{\circ} \mathrm{C}$. Propionaldehyde $(1.04 \mathrm{ml}, 15 \mathrm{mmol})$ was added over a period of 10 minutes. The solution was stirred for $2 \mathrm{hr}$ at $-78^{\circ} \mathrm{C}$ and then warmed to room temperature and stirred for another 3 hours. The reaction was quenched by addition of an aqueous solution of $\mathrm{HCl}(10 \%)$. After evaporating the solvent, the residue was redissolved in acetone $(50 \mathrm{ml})$, and Jones reagent was added dropwise into the solution. The color changed from red to green and then to red again. The reaction was stopped when the red color persisted. Evaporating the solvent gave an oil-like substance. The material was purified using flash chromatography on silica gel using dichloromethane-hexane (3:1, with $1 \%$ ethyl acetate) as eluent to give a white crystal $0.965 \mathrm{~g}$ (yield $45 \%) .{ }^{1} \mathrm{H} \mathrm{NMR}\left(\mathrm{CDCl}_{3}\right): \delta 1.27\left(\mathrm{t}, \mathrm{CH}_{3}\right.$, $6 \mathrm{H}), 3.14$ (q, $\left.\mathrm{CH}_{2}, 4 \mathrm{H}\right), 3.39$ (s, $\left.\mathrm{OCH}_{3}, 6 \mathrm{H}\right), 7.14$ (d, $2 \mathrm{H}), 7.33$ (t, $2 \mathrm{H}), 7.45(\mathrm{t}, 2 \mathrm{H}), 7.98(\mathrm{~d}, 2 \mathrm{H})$, $8.19(\mathrm{~d}, 2 \mathrm{H}) .{ }^{13} \mathrm{C}$ NMR $\left(\mathrm{CDCl}_{3}\right) \delta 8.9,36.7,62.2$, $125.4,125.8,125.9,128.5,129.5,130.2,130.9$, 134.4, 135.6, 153.9, 205.3. Element analysis: Calculated: C 78.85\%, H 6.14\% Found: C 78.68\%, H $6.15 \%$.

Synthesis of (S)-(+)-6,6'-dipropionoyl-2,2'dimethoxy-1,1'-binaphthyl (8)

This compound was prepared from commercial $(S)$ (+)-6,6'-dibromo-2,2'-dimethoxy-1,1'-binaphthyl (steoroisomer of 2) following the same procedures as described in compound 4 . The ${ }^{1} \mathrm{H}$ NMR and ${ }^{13} \mathrm{C}$ NMR characterization resembles that for 4 .

\section{General procedure for the polymerization}

To an oven-dried flask equipped with a Teflon valve containing a spin-bar was charged with $\mathrm{Pd}(\mathrm{OAc})_{2}(6.7 \mathrm{mg}, 0.0299 \mathrm{mmol}), \mathrm{P}(t-\mathrm{Bu})_{3}(3.3 \mathrm{mg}$, $0.0163 \mathrm{mmol})$ and $t$-BuONa (100 $\mathrm{mg}, 1.04 \mathrm{mmol})$. The Schlenk tube was degassed and refilled with nitrogen. Arene dihalide $(0.5 \mathrm{mmol})$, diketone $(0.5 \mathrm{mmol})$ and THF $(2 \mathrm{ml})$ were added. The resulting mixture was heated under nitrogen to $70^{\circ} \mathrm{C}$ for $24 \mathrm{hr}$. The mixture was cooled to room temperature and precipitated into methanol. The polymer obtained was redissolved in THF and reprecipitated several times to yield an off-white powder. The yields range from $60-92 \%$. Poly- $(\boldsymbol{R})-(+)-9$ and poly-(R)-(-)-10 were synthesized by the reaction of 4 with 1,4-phenylene and 4,4'-biphenylene, respectively. Poly-(S)-(+)-11 and poly-(S)-(-)-12 were synthesized by the reaction of 7 with 1,4-phenylene and 4,4'-biphenylene, respectively. Poly-(R)-(+)-9. ${ }^{1} \mathrm{H} \mathrm{NMR}\left(\mathrm{CDCl}_{3}\right): \delta 1.47\left(\mathrm{CH}_{3}, 6 \mathrm{H}\right), 3.70\left(\mathrm{OCH}_{3}\right.$, $6 \mathrm{H}), 4.75(\mathrm{CH}, 2 \mathrm{H}), 6.99-8.49(\mathrm{H}-\mathrm{Ar}, 14 \mathrm{H})$. ${ }^{13} \mathrm{C} \mathrm{NMR}\left(\mathrm{CDCl}_{3}\right): \delta 19.8,47.2,56.7,114.3,118.7$, 
$125.4,128.1,128.6,131.3,131.8,132.0,136.2$, 140.3, 157.2, 200.2. Poly-(R)-(-)-10. ${ }^{1} \mathrm{H}$ NMR $\left(\mathrm{CDCl}_{3}\right): \delta 1.57(\mathrm{CH} 3,6 \mathrm{H}), 3.71\left(\mathrm{OCH}_{3}, 6 \mathrm{H}\right)$, $4.82(\mathrm{CH}, 2 \mathrm{H}), 7.03-8.55(\mathrm{H}-\mathrm{Ar}, 18 \mathrm{H}) .{ }^{13} \mathrm{C} \mathrm{NMR}$ $\left(\mathrm{CDCl}_{3}\right): \delta 19.6,47.2,56.4,114.1,118.5,125.2$, $127.5,127.8,128.1,131.0,131.5,131.7,135.9$, 139.1, 140.6, 156.9, 199.8. Poly-(S)-(+)-11. ${ }^{1} \mathrm{H}$ NMR $\left(\mathrm{CDCl}_{3}\right): \delta 1.54\left(\mathrm{CH}_{3}, 6 \mathrm{H}\right), 3.25\left(\mathrm{OCH}_{3}\right.$, m, $6 \mathrm{H}), 4.69$ (CH, $2 \mathrm{H}), 6.90-8.19(\mathrm{H}-\mathrm{Ar}, 14 \mathrm{H})$. Poly-(S)-(-)-12. ${ }^{1} \mathrm{H}$ NMR $(\mathrm{CDCl} 3): \delta 1.62\left(\mathrm{CH}_{3}\right.$, $6 \mathrm{H}), 3.25\left(\mathrm{OCH}_{3}, \mathrm{~m}, 6 \mathrm{H}\right), 4.81(\mathrm{CH}, 2 \mathrm{H}), 6.98-$ $8.19(\mathrm{H}-\mathrm{Ar}, 18 \mathrm{H}) .{ }^{13} \mathrm{C} \mathrm{NMR}\left(\mathrm{CDCl}_{3}\right): \delta 18.6$, $51.8,62.4,124.8,125.2,125.7,127.3,128.3,128.9$, 129.4, 130.0, 131.1, 134.3, 135.3, 139.4, 140.0, 153.4, 205.2. Poly-(S)-(+)-10 was synthesized by reaction of 8 with $4,4^{\prime}$-biphenylene with the ${ }^{1} \mathrm{H}$ NMR characterization the same as for poly- $(\boldsymbol{R})$ (-)-10.

\section{Results and discussion}

Previously a facile synthesis of polyketones by cross-coupling condensation polymerization has been reported by our research group [30]. To further synthesize optically-active chiral polyketones, the initial attempt involved the reaction of $(R)-(+)-$ 6,6'-dibromo-2,2'-dimethoxy-1, $1^{\prime}$-binaphthyl (2) with 1,4-diacetylbenzene under the reported crosscoupling conditions. The reaction took place read- ily to yield a solid which was insoluble in any organic solvents. Therefore, it has been difficult to process and characterize the resulted polymer using solution techniques. We reasoned that the infusibility might be attributed to the rigid polymer backbone structures. In order to prepare soluble chiral polyketones, a model reaction of compound $\mathbf{2}$ with 1,4-dipentanoylbenzene (Figure 2) was conducted and surprisingly the resulting polymer product was completely soluble in common organic solvents including methylene chloride, chloroform, THF and DMF. We believed that the solubility was enhanced by the asymmetric center introduced in the polymer backbone. The structures of the polymers were studied by ${ }^{1} \mathrm{H}$ NMR spectroscopy. The peaks at $\delta 4.75 \mathrm{ppm}$ in ${ }^{1} \mathrm{H}$ NMR and at $\delta 200 \mathrm{ppm}$ in ${ }^{13} \mathrm{C}$ NMR corresponded to methine and carbonyl resonances in the polymer, respectively. The molecular weight of the polymers was however low as revealed by GPC $\left(M_{w}=7900\right)$. It was speculated that the low molecular weight might associate with the relative low oxidative addition activity of carbon-bromide bond with palladium complexes. To test this thought, a further experiment was carried out by polymerization of 1,4-dipentanoylbenzene with $6,6^{\prime}$-diiodo-2,2'-dimethoxy-1,1'-binaphthyl (3), which was synthesized with $83 \%$ yield by nickel-catalyzed exchange reaction of 2 with KI following a reported procedure [40] (Figure 1). The<smiles>Oc1ccc2cc(Br)ccc2c1-c1c(O)ccc2cc(Br)ccc12</smiles>

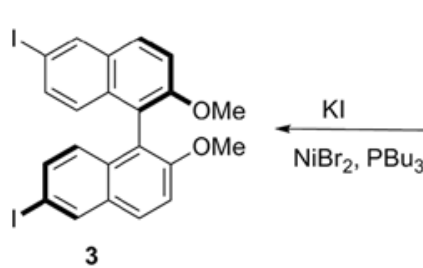
$\mid \mathrm{CH}_{3} \mathrm{I}, \mathrm{K}_{2} \mathrm{CO}_{3}$
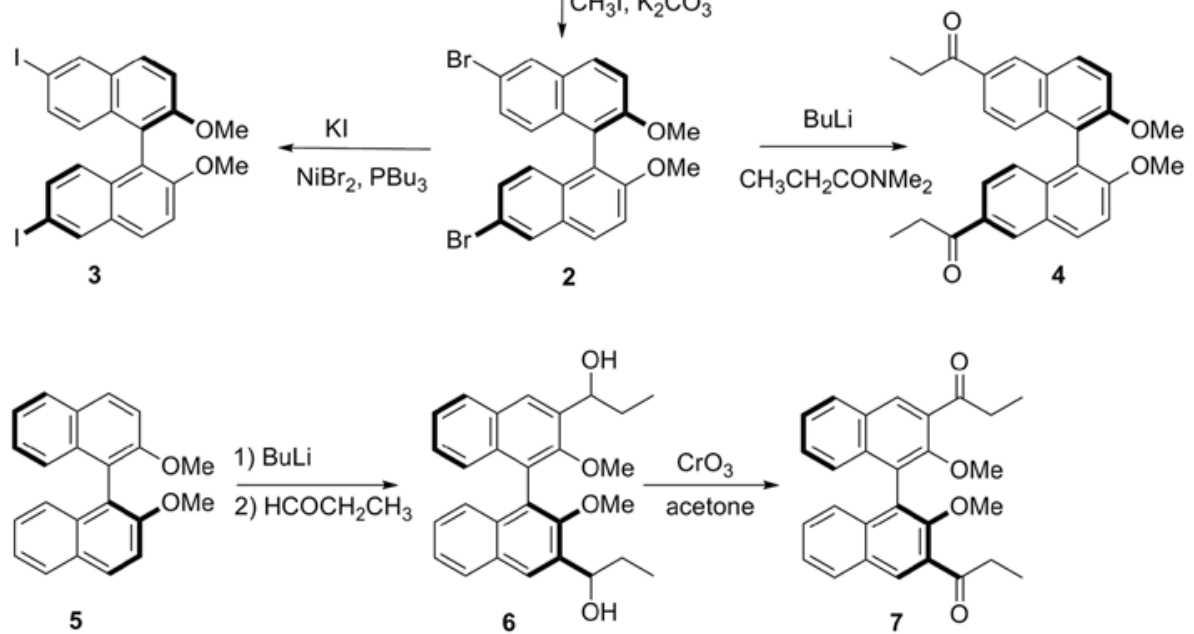

Figure 1. Synthesis of optically active monomers 


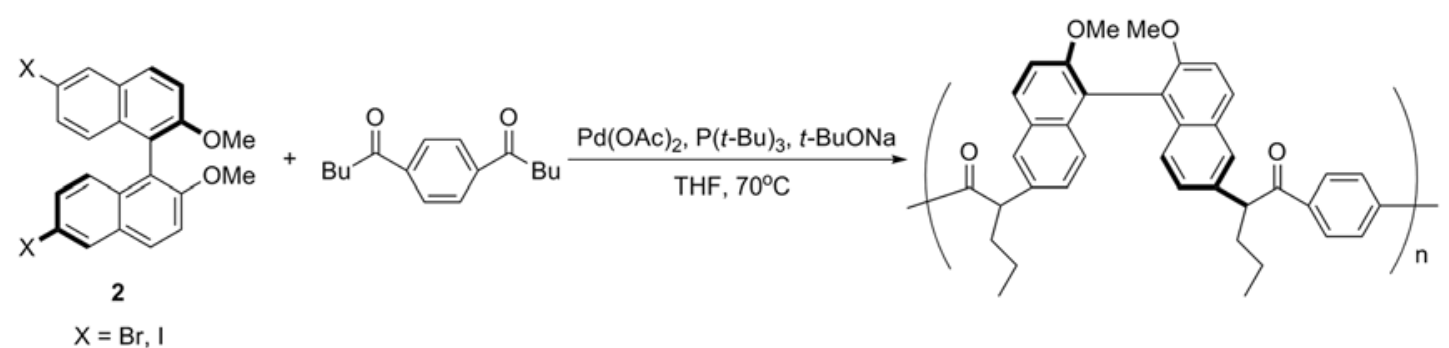

Figure 2. Palladium catalyzed polymerization of 2 with 1,4-dipentanoylbenzene

product can be easily isolated and purified by recrystallization. The substitution of both bromides by iodides was confirmed by the disappearance of quaternary aromatic carbon resonance next to the bromide at $\delta 117.3 \mathrm{ppm}$ and the appearance of a peak at $88.8 \mathrm{ppm}$ corresponding to the quaternary aromatic carbon resonance adjacent to iodide in ${ }^{13} \mathrm{C}$ NMR spectra. The driving force for such a reaction is the formation of thermodynamically more stable $\mathrm{KBr}$. Indeed, the condensation polymerization of $\mathbf{3}$ and 1,4-dipentanoylbenzene yielded polymers with slightly higher molecular weights $\left(M_{w}=8900\right)$.

By studying the structures of the monomers, it was noticed that compounds $\mathbf{2}$ and $\mathbf{3}$ possessed sterically bulky binaphthyl rings, which might hamper the subsequent displacement of the bromides or iodides in the intermediates formed from the oxida- tive addition of palladium complexes. To reduce the steric hindrance, we looked into the polymerization of $(R)-(+)-6,6^{\prime}$-dialkanoyl-2,2'-dimethoxy$1,1^{\prime}$-binaphthyl (4) with 1,4-dihalobenzene or $4,4^{\prime}$-dihalobiphenyl, where the alkanoyl groups were directly connected onto the binaphthyl rings and the halides were attached to the less hindered phenyl groups. Compound $\mathbf{4}$ was synthesized in good yield by first treating 2 with BuLi to generate 6,6'-dilithio-2,2'-dimethoxy-1,1'-binaphthyl, which further reacted with $\mathrm{N}, \mathrm{N}$-dimethylpropionamide. The products were characterized by both ${ }^{1} \mathrm{H}$ and ${ }^{13} \mathrm{C}$ NMR spectroscopy. The polymerization was carried out by condensation reaction of $\mathbf{4}$ and 1,4dibromobenzene to yield main-chain chiral polymers (Figure 3). A significant increase in the molecular weight was observed (Table 1). This supports our rationale that steric hindrance has
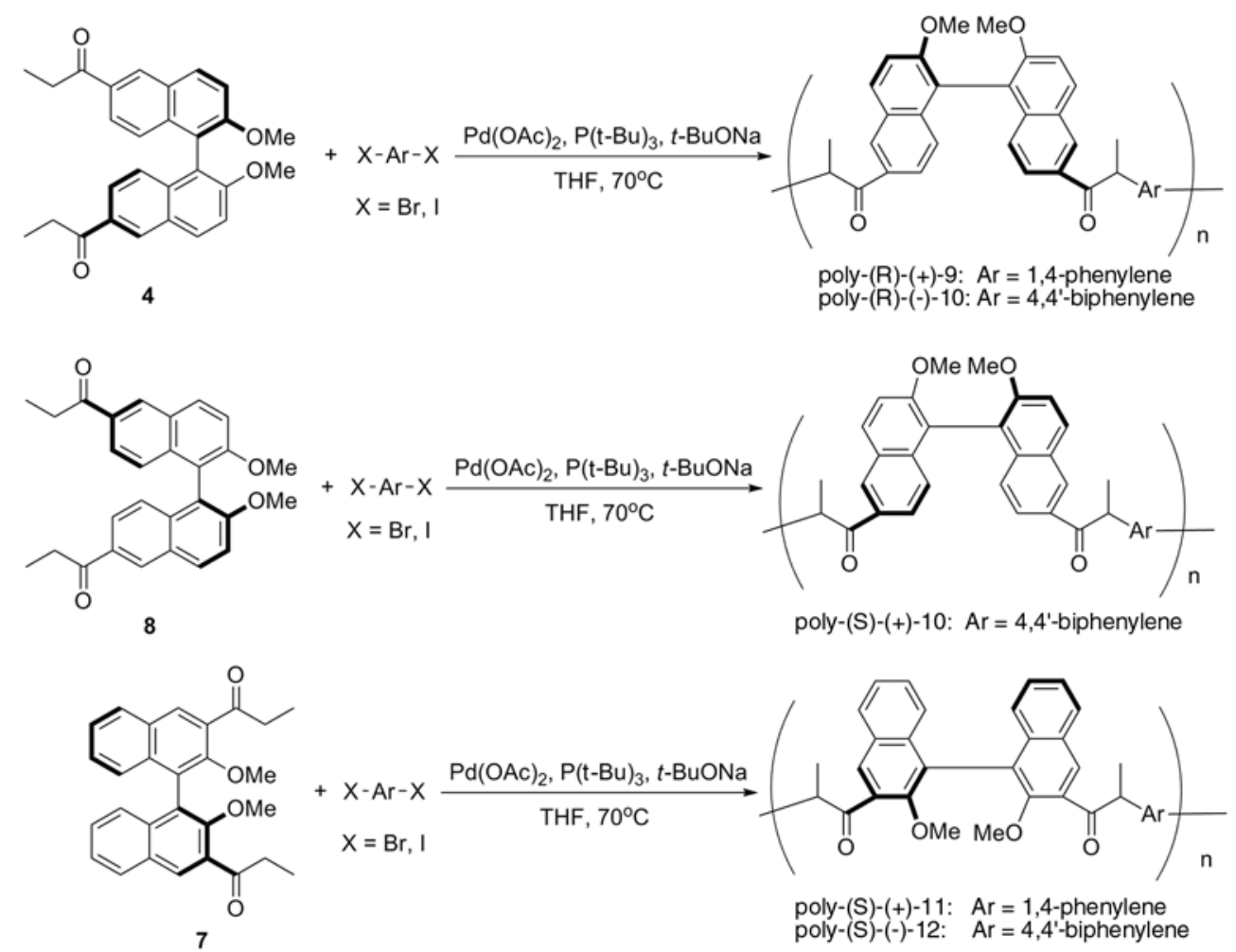

Figure 3. Construction of optically active main-chain polymers 
Table 1. Polymerization results, optical rotation, and solubility

\begin{tabular}{|c|c|c|c|c|}
\hline Entrya & $\mathbf{M}_{\mathbf{w}}$ & PDI & {$[\alpha]_{\mathbf{D}}$} & Soluble in \\
\hline poly- $(R)-(+)-9$ b & 16800 & 2.44 & 1.65 & $\mathrm{CHCl}_{3}, \mathrm{CH}_{2} \mathrm{Cl}_{2}$, THF, DMF, partially in Bz \\
\hline poly-(R)-(-)-10 ${ }^{c}$ & 19400 & 2.77 & -108.30 & $\mathrm{CHCl}_{3}, \mathrm{CH}_{2} \mathrm{Cl}_{2}$, THF, DMF, partially in Bz \\
\hline poly-(S)-(+)-10c & 21200 & 2.61 & 78.10 & $\mathrm{CHCl}_{3}, \mathrm{CH}_{2} \mathrm{Cl}_{2}$, THF, DMF, partially in Bz \\
\hline poly- $(S)-(+)-11^{b}$ & 8260 & 2.36 & 5.78 & $\mathrm{CHCl}_{3}, \mathrm{CH}_{2} \mathrm{Cl}_{2}, \mathrm{THF}, \mathrm{DMF}, \mathrm{Bz}$ \\
\hline poly-(S)-(-)-12c & 10800 & 2.24 & -60.10 & $\mathrm{CHCl}_{3}, \mathrm{CH}_{2} \mathrm{Cl}_{2}, \mathrm{THF}, \mathrm{DMF}, \mathrm{Bz}$ \\
\hline
\end{tabular}

${ }^{a} R$ and $S$ denote the stereoconfigurations of the optically active monomers

${ }^{b}$ the linker between the chiral binaphthyls is 1,4-phenylene

${ }^{c}$ the linker between the chiral binaphthyls is $4,4^{\prime}$-biphenylene

played a significant role in effecting the outcome of this type of polymerization. Similarly, reaction of 4,4'-dihalobiphenyl with 4 under the same conditions also yielded polymers with enhanced molecular weights.

To prepare other type of chiral polymers, the reactions of (S)-(-)-3,3'-dihalo-2,2'-dimethoxy-binaphthyl with 1,4-dipropionylbenzene was also investigated. However, only oligomers were obtained and the products could not be clearly identified. This might be a combination effect of deactivation of the palladium intermediate and the steric hindrance of binaphthyl rings. Similarly, the polymerization of (S)-(-)-3,3'-dipropionyl-2,2'-dimethoxybinaphthyl (7) was also studied, where halides are not directly bound to the bulky binaphthyl ring. In contrast to the synthesis of $\mathbf{4}$, the reaction of $(S)-(-)-3,3^{\prime}-$ dihalo-2,2'-dimethoxy-binaphthyl with BuLi and subsequent treatment of the resulting product with $\mathrm{N}, \mathrm{N}$-dimethylpropinylamide was sluggish and yielded no desired products, which was attributed to the stabilization of the lithium ion imposed from the adjacent methoxy and less electrophilic nature of the amide. This has been confirmed by the readily reaction of 3,3'-dilithio-2,2'-dimethoxybinaphthyl with propionaldehyde to produce an alcohol intermediate $\mathbf{6}$ in high yield. Compound $\mathbf{6}$ was easily oxidized by Jones agent to give $\mathbf{7}$ in good yield (Figure 1). The condensation polymerization of 7 with 1,4-dihalobenzene and 4,4'-dihalobiphenylene proceeded smoothly yielding main-chain chiral polymers with molecular weights up to 11000 (Figure 3). The experimental result supports our analysis on the reactivity of this type of polymerization reactions.

The structures of the resulting polymers were characterized by both ${ }^{1} \mathrm{H}$ and ${ }^{13} \mathrm{C}$ NMR spectroscopy. Chiral optical properties were studied by polarimeter and circular dichroism (CD) spectroscopy. Fig-

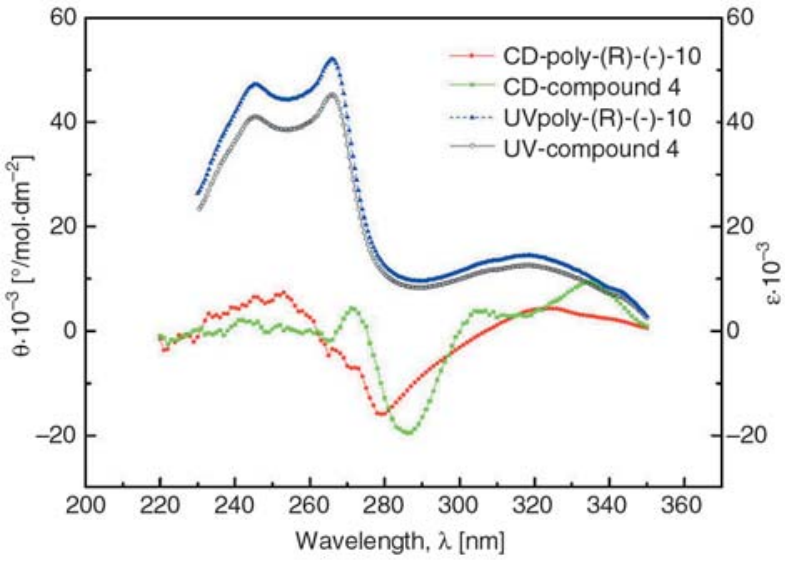

Figure 4. UV-Vis and CD spectra of poly-(R)-(-)-10 and monomer 4

ure 4 shows the UV-Vis and CD spectrum of poly$(\boldsymbol{R})-(-)-10$ and its corresponding monomer (4). The UV absorptions of the chiral polymer and monomer are nearly identical. The CD spectrum of poly- $(\boldsymbol{R})$ $(-)-10$ exhibits slightly hypsochromic shift as compared to that of 4 . Large optical rotations were observed for chiral polymer poly-(R)-(-)-10 $\left([\alpha]_{\mathrm{D}}=-108.3\right)$ comparable to those of the pure monomer $4\left([\alpha]_{\mathrm{D}}=-112.7\right)$. As a comparison, poly-(S)-(+)-10 exhibited a large optical rotation of $[\alpha]_{\mathrm{D}}=78.1$. The different optical activity for poly$(R)-(-)-10$ and poly-(S)-(+)-10 was further evidenced by circular dichroism (Figure 5). It is interesting to note that the substitutents can alter the direction of the polarized light. For polymers with $R$ stereoconfiguration, more rigid linker such as biphenylene between the two chirality generating binaphthyl groups give polymers with large negative optical rotations $\left([\alpha]_{\mathrm{D}}=-108.3\right.$, Table 1$)$ indicating that the binaphthyl chiral environment is not disturbed. When shorter bridge such as 1,4phenylene is used, the sign of the optical rotation has reversed to slightly positive $\left([\alpha]_{D}=1.65\right.$, Table 1), an indication of the change of configuration of the polymer chain. CD spectra of the poly- 


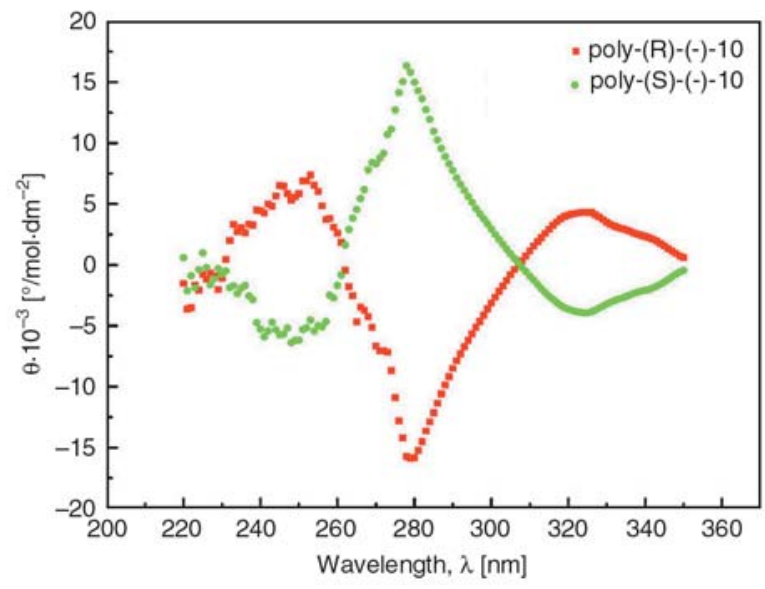

Figure 5. CD spectra of poly-(R)-(-)-10 and poly-(S)-(+)-10

mers are similar to those of the monomers, suggesting little formation of secondary chiral conformations, and polymers maintain their original rigidity. It is important to note that the configuration of the newly created chiral centers in the chiral polymers might be important to the properties of the resulting main-chain chiral polymers. Further investigations on the stereochemistry of the chiral polymers and its effect on properties of chiral polymers will be conducted to delineate the structure-property relationship. Solubility tests indicate that the synthesized polymers are readily soluble in organic solvents such as chloroform, methylene chloride, benzene, DMF and THF (Table 1). Thermal properties of the synthesized polymers such as measurements of glass transition temperatures $\left(T_{g}\right)$, thermal decomposition experiments $\left(T_{d}\right)$ and other measurements on physical properties are currently in progress and will be reported in due time.

\section{Conclusions}

A simple route for the synthesis of the first soluble optically active main-chain chiral polyketones has been demonstrated using palladium catalyzed condensation reactions of dihalide and diketones. The reactivity of the monomers can be tuned by exchanging the positions of halide and alkanoyl substituents on the aryl rings. Higher molecular weight polymers can be obtained by reacting binaphthyl alkyl ketones with 1,4-dihalobenzene or $4,4^{\prime}$-dihalobiphenyl. Optical rotation and CD data indicate that the polymers adopt little helical configuration. The high solubility of the synthesized main-chain chiral aliphatic aromatic polyketones allows for materials to be made in the form of thin films and will expand potential applications of polyketones in various areas including chiral separation and recognition. Further measurements on thermal properties of the synthesized materials and synthetic strategy development of higher molecular weight poly(alkyl-aryl ketone) are currently under investigation.

\section{References}

[1] Teraguchi M., Mottate K., Kim S-Y., Aoki T., Kaneko T., Hadano S., Masuda T.: Synthesis of chiral helical poly(hydroxyl-containing phenylacetylene) membranes by in-situ depinanylsilylation and their enantioselective permeabilities. Macromolecules, 38, 6367-6373 (2005).

[2] Nakano T., Satoh Y., Okamoto Y.: Synthesis and chiral recognition ability of a cross-linked polymer gel prepared by a molecular imprint method using chiral helical polymers as templates. Macromolecules, 34, 2405-2407 (2001).

[3] Itsuno S.: Chiral polymer synthesis by means of repeated asymmetric reaction. Progress in Polymer Science, 30, 540-558 (2005).

[4] Teraguchi M., Masuda T.: Poly(diphenylacetylene) membranes with high gas permeability and remarkable chiral memory. Macromolecules, 35, 1149-1151 (2002).

[5] Pu L.: 1,1'-Binaphthyl dimers, oligomers, and polymers: Molecular recognition, asymmetric catalysis, and new materials. Chemical Reviews, 98, 2405-2494 (1998).

[6] Wulff G.: Hauptkettenchiralität und optische Aktivität von Polymeren aus C-C-Ketten. Angewandte Chemie, 101, 22-38 (1989).

[7] Xue Q. B., Kimura T., Fukuda T., Shimada S., Matsuda H.: Synthesis and lyotropic liquid crystal properties of chiral helical polycarbodiimides. Liquid Crystals, 31, 137-143 (2004).

[8] van Beijnen A. J. M., Nolte R. J. M., Naaktgeboren A. J., Zwikker J. W., Drenth W., Hezemans A. M. F.: Helical configuration of poly(iminomethylenes). Synthesis and CD spectra of polymers derived from optically active isocyanides. Macromolecules, 16, 1679 1689 (1983).

[9] Nozaki K.: Asymmetric catalytic synthesis of polyketones and polycarbonates. Pure and Applied Chemistry, 76, 541-546 (2004).

[10] Kakuchi T., Obata M.: Synthesis and mechanism of a main-chain chiral polymer based on asymmetric cyclopolymerization. Macromolecular Rapid Communications, 23, 395-406 (2002).

[11] Touchard F., Fache F., Lemaire M.: Polythioureas: Main chain chiral polymers in hydride transfer hydrogenation. European Journal of Organic Chemistry, 2000, 3787-3792 (2000). 
[12] Nozaki K., Sato N., Takaya H.: Highly enantioselective alternating copolymerization of propene with carbon monoxide catalyzed by a chiral phosphine-phosphite-palladium(II) complex. Journal of American Chemical Society, 117, 9911-9912 (1995).

[13] Sperrle M., Consiglio G.: Diastereo- and enantioselectivity in the co-oligomerization of propene and carbon monoxide to dimethyl-4-oxoheptanedioates. Journal American Chemical Society, 117, 12130-12136 (1995).

[14] Nazaki K., Sato N., Tonomura Y., Yasutomi M., Takaya H., Hiyama T., Matsubara T., Koga N.: Mechanistic aspects of the alternating copolymerization of propene with carbon monoxide catalyzed by $\mathrm{Pd}(\mathrm{II})$ complexes of unsymmetrical phosphine-phosphite ligands. Journal of American Chemical Society, 119, 12779-12795 (1997).

[15] Buese M. A., Hogen-Esch T. E.: Oligomerization of vinyl monomers. 17. Stereoselective methylation of 1lithio-1,3-bis(phenylsulfinyl)butane. Kinetic vs. thermodynamic control in the formation of diastereomeric ion pairs. Journal of American Chemical Society, 107, 4509-4513 (1985).

[16] Yamaguchi H., Iwama T., Hayashi T., Doiuchi T.: Asymmetric induction polymerization of monomer salts prepared from 1,3-butadiene-1-carboxylic acid and optically active amines. Die Makromolekulare Chemie, 191, 1243-1251 (1990).

[17] Odian G.: Principles of polymerization. Wiley, New York (1991).

[18] Colquhoun H. M., Paoloni F. P. V., Drew M. G. B., Hodge P.: Dithioacetalisation of PEEK: A general technique for the solubilisation and characterization of semi-crystalline aromatic polyketones. Chemical Communications, 32, 3365-3367 (2007).

[19] Liu X. B., Du R. H., Hao L. L., Wang S., Cao G. P., Jiang H.: Synthesis, characterization and rheological property of biphenyl-based polyarylene ether nitrile copolymers. Express Polymer Letters, 1, 499-505 (2007).

[20] Ozarslan Ö., Yildiz E., Yilmaz T., Güngör A., Kuyulu A.: Novel poly(arylene ether ketone ketone)s synthesized by Friedel-Crafts acylation. Macromolecular Chemistry and Physics, 199, 1887-1893 (1998).

[21] Johnson R. N., Farnham A. G., Clendinning R. A., Hale W. F., Meriiam C. N.: Poly(aryl ethers) by nucleophilic aromatic substitution. I. Synthesis and properties. Journal of Polymer Science Part A-1: Polymer Chemistry, 5, 2375-2398 (1967).

[22] Bonner W. H.: Aromatic polyketones. US Patent 3065205, USA (1962).

[23] Yu Y. K., Xiao F., Cai M. Z.: Synthesis and properties of poly(aryl ether ketone ketone)/poly(aryl ether ether ketone ketone) copolymers with pendant cyano groups. Journal of Applied Polymer Science, 104, 3601-3606 (2007).

[24] Chiechi R. C., Sonmez G., Wudl F.: A robust electroactive n-dopable aromatic polyketone. Advanced Functional Materials, 15, 427-432 (2005).
[25] Guo Q., Bo S., Chen T.: Synthesis of macrocyclic arylene ketone oligomers containing the phthaloyl moiety by Friedel-Crafts acylation reaction. Chemistry Letters, 33, 414-415 (2004).

[26] Danforth R. L., Machado J. M., Jordaan J. C. M.: Aliphatic polyketones - A new family of engineering thermoplastics. Plastic Engineering, 52, 77-79 (1996).

[27] Jiang Z., Sen A.: Palladium(II)-catalyzed isospecific alternating copolymerization of aliphatic alpha-olefins with carbon monoxide and isospecific alternating isomerization cooligomerization of a 1,2-disubstituted olefin with carbon monoxide. Synthesis of novel, optically active, isotactic 1,4- and 1,5-polyketones. Journal of American Chemical Society, 117, 4455-4467 (1995).

[28] Nozaki K., Kosaka N., Graubner V. M., Hiyama T.: Methylenation of an optically active $\gamma$ polyketone: Synthesis of a new class of hydrocarbon polymers with main-chain chirality. Macromolecules, 34, 61676168 (2001).

[29] Guo J., Wang B., Zhu C.: Copolymerization of carbon monoxide and styrene catalyzed by resin-supported palladium polymer. Express Polymer Letters, 1, 6976 (2007).

[30] Wang D., Wei P., Wu Z.: A new polymerization reaction: Synthesis of soluble polyketones and poly(arylenevinylene)s. Macromolecules, 33, 68966898 (2000).

[31] Pu L.: The study of chiral conjugated polymers. Acta Polymerica, 48, 116-141 (1997).

[32] Hu Q. S., Huang W. S., Pu L.: A new approach to highly enantioselective polymeric chiral catalysts. Journal of Organic Chemistry, 63, 2798-2799 (1998).

[33] Hu Q-S., Huang W-S., Vitharana D., Zheng X-F., Pu L.: Functionalized major-groove and minor-groove chiral polybinaphthyls: Application in the asymmetric reaction of aldehydes with diethylzinc. Journal of American Chemical Society, 119, 12454-12464 (1997).

[34] Liu Y., Zhang S., Miao Q., Zheng L., Zong L., Cheng Y.: Fluorescent chemosensory conjugated polymers based on optically active polybinaphthyls and 2,2' bipyridyl units. Macromolecules, 40, 4839-4847 (2007).

[35] Jaycox G. D.: Stimuli-responsive polymers. VII. Photomodulated chiroptical switches: Periodic copolyaramides containing azobenzene, phenylene, and chiral binaphthylene main-chain linkages. Journal of Polymer Science, Part A: Polymer Chemistry, 42, 566-577 (2004).

[36] Hu Q-S., Vitharana D., Liu G. Y., Jain V., Wagaman M. W., Zhang L., Lee R. T., Pu L.: Conjugated polymers with main chain chirality. 1 . Synthesis of an optically active poly(arylenevinylene). Macromolecules, 29, 1082-1084 (1996).

[37] Pu L.: Recent developments in asymmetric catalysis using synthetic polymers with main chain chirality. Tetrahedron: Asymmetry, 9, 1457-1477 (1998). 
[38] Toda F., Tanaka K., Stein Z., Goldberg I.: Optical resolution of binaphthyl and biphenanthryl diols by inclusion crystallization with $\mathrm{N}$-alkylcinchonidium halides. Structural characterization of the resolved materials. Journal of Organic Chemistry, 59, 57485751 (1994).
[39] Minatti A., Dötz K. H.: Quinoid BINOL-type compounds as a novel class of chiral ligands. Tetrahedron: Asymmetry, 16, 3256-3267 (2005).

[40] Meyer G., Rollin Y., Perichon J.: Electrocatalysis by nickel complexes, of the synthesis of aromatic or vinylic from corresponding brominated derivatives (in French). Tetrahedron Letters, 27, 3497-5000 (1986). 